Financial Markets, Institutions and Risks, Volume 3, Issue 4, 2019

ISSN (online) - 2521-1242 ISSN (print) - 2521-1250

\title{
Firm Growth vs. External Growth: A Behavioral Approach
}

Khadidja Nemmiche, ORCID: https://orcid.org/0000-0002-7034-7769

Dr., University Centre of Maghnia, Maghnia, Algeria

Abdelkader Nassour, ORCID: https://orcid.org/0000-0002-3368-8783

Dr., Faculty of economics and commerce and Management, University of Sidi Bel Abbes, Sidi-bel-Abbes, Algeria

Mehdi Bouchetara, ORCID: https://orcid.org/0000-0001-9826-8985

Dr., Higher National School of Management, El Harrach, Algeria

\begin{abstract}
A firm is a market contradiction: as a firm grows, the market shrinks. The basis of this statement are theoretical approaches, which are called theories of the company. This work is aimed at determining the boundaries of the company in a dynamic perspective with the aim of finding effective solutions to the process of its growth. The study notes that opportunism as a behavioral factor, as Williamson noted, incurs significant operating costs that encourage the firm to change its boundaries. Therefore, the work focuses on this factor to create a systematic image and a general theoretical basis for changes that affect the size of the company. The main objective of the study is to determine the relationship between the opportunistic behavior of economic agents and the internal and external growth of the company. The author notes that opportunism is an unlawful behavior, often taking place in a double relationship between two legally independent parties and is a consequence of external and internal uncertainty and information asymmetry. The study postulates that the concept of trust, information transparency, or information balance between parties remains a dream for both theorists and practitioners. It has been ascertained that information transparency and a complete understanding between economic entities are difficult to implement in the context of the priority role of personal good over public or, at least, mutually beneficial. The results of the study confirmed the influences of opportunistic actions of economic entities, as predicted in the framework of transaction costs theory, the organizational changes of a company, its scale. The study made it possible to justify the presence of a positive effect of illegal actions on the internal expansion of the company and the negative, expanding the external structure.
\end{abstract}

Keywords: Sourcing, External Relationships, Internal Relationships, Opportunism.

JEL Classification: D21, D23, L22, L25.

Cite as: Nemmiche, K., Nassour Ab., Bouchetara, M. (2019). Firm growth vs. external growth: a behavioral approach. Financial Markets, Institutions and Risks, 3(4), 16-23. http://doi.org/10.21272/fmir.3(4). 1623.2019.

(C) The Authors, 2019. This article is published with open access at Sumy State University.

\section{Introduction}

For several centuries, the firm and the market have been the only two poles of economic activity. The market offers what the firm cannot/ does not want; and the firm manages what the market cannot. This indisputable proposal has experienced academic growth after the Coasian contribution on the firm and the movement of its borders. More precisely, in 1937, Coase raised for the first time in the literature the issue of the coexistence of the two economic poles: the firm and the market. In responding to Robertson's question (1928), the author pointed out that the firm exists because transaction costs occur when the market is used. According to the author, the firm is expanding until the internal coordination costs become high. The author therefore presented a simplistic model of dynamism regarding the size of the firm. Coase (1937) opened the door to an economic and managerial problem previously neglected by the classics and neoclassics.

Later, Williamson $(1971,1979)$ was able to expand the Coasian proposal by focusing particularly on the notion of transaction costs and its impact on the firm's border movement. Williamson's work (1979, 1988, and 1993) gives an economic interpretation to Sourcing's decision by introducing a new theory called Transaction Cost Theory. 
Financial Markets, Institutions and Risks, Volume 3, Issue 4, 2019

ISSN (online) - 2521-1242 ISSN (print) - 2521-1250

The TCT indicates that the firm internalizes a transaction if the transaction costs generated by the use of the market are high. Internalization means from another angle a growth in the size of the firm. Conversely, an inward narrowing is produced when the firm uses the market or the cooperation as a hybrid solution between the firm and the market (Williamson, 1971, 2000, 2002).

While Coase (1937) left the notion of transaction costs unclear by simply considering it as the raison d'être of the firm's border movement, Williamson $(1979,1981)$ deepens into this crucial factor and analyzes the firm's raison d'être.

According to the TCT, transaction costs are a function of the characteristics of the transaction (asset specificity, uncertainty and frequency) and the behavioral characteristics of the economic actors involved in the transaction (opportunism and limited rationality). As a result, opportunism is one of the factors that influence transaction costs and therefore the firm's organizational orientation from an economic perspective.

In the following, we will broaden the market/hierarchy dichotomy before highlighting the role that opportunism plays in determining the firm's organizational change. Afterwards, a literature review will be conducted to underline the importance of this factor in representing the firm's border movement according to previous studies on the same subject.

The idea of the strong possibility of the TCT to explain the firm's internal growth or the firm's reciprocal orientation is launched, depending on the effect of opportunism. To do this, we will compare the assumptions of the TCT with the results of previous research aimed at repositioning the application framework of such a theory.

\section{From Firm/Market to Firm/Market/Cooperation:}

In the literature before Coasien, the firm is perceived as a black box; a fictitious entity and a simple process of producing goods sold in the market. The internal organization of the firm remained a neglected or even unthinkable subject (Palloix, 2002).

With Coase's famous article (1937), the firm became a particular organization, independent of the market; with a specific internal structure and a particular and complex management mode. Coase (1937) was able to open the door to analyze that focused on the firm and the market as two organizational arrangements that coexisted but differently. The firm and the market according to Coase (1937) have the same economic function, which is the coordination of resources. Market transactions are carried out through the price mechanism. While within the firm, the role of the entrepreneur is dominated by supervising hierarchical transactions.

With the opening of the firm's black box, the firm's organizational boundaries became a crucial object of study that was clearly expanded by the researchers. This enlargement has given rise to a third form of coordination that falls between the two extremes of economic activity. This is the form of inter-firm cooperation that represents itself as a new, independent and distinct governance structure (Ménard, 2004). The work of Williamson $(1979,1991)$ and Imai and Itami (1984) confirmed the stability of this new practice, which is neither the firm's nor the market's responsibility.

In the following table, a comparison between the three governance structures according to the main points of differentiation reveals the similarity, difference and complementation between them:

Table. 1. Comparison between the three organizational forms

\begin{tabular}{|l|l|l|l|}
\cline { 2 - 3 } \multicolumn{1}{c|}{} & Hierarchy & Cooperation \\
\hline Relational nature between parties & Dependents & Independents \\
\hline Decision-making nature & Unilateral & Bilateral \\
\hline Identification of the parties & Compulsory & Compulsory \\
\hline Type of contract & Subordination contract & Neoclassical contract \\
\hline Contract duration & Long & Middling & Bilateral \\
\hline Sharing of rights and responsibilities & Inequitable & Equitable & Slassical contract \\
\hline
\end{tabular}

Source: According to the authors.

\section{Opportunism: the raison d'être}

Opportunism is a behavior that is probably perceived as illegal and an instinctive nature of an individual seeking to maximize his personal utility at the expense of others. As a pillar of the transaction cost approach, Williamson (1988, p. 68) defines it as: "a deep condition of self interest seeking that contemplates guile". 
Financial Markets, Institutions and Risks, Volume 3, Issue 4, 2019

ISSN (online) - 2521-1242 ISSN (print) - 2521-1250

In the economic literature, opportunism can occur when one of the two contracting parties has more information about a given transaction. This allows him to convert the transaction to his sole benefit.

This behavior, which threatens the continuity of the bipolar relationship, takes two forms: adverse selection and moral hazard. As for the first form, it is also called pre-contractual opportunism; because it may appear before the contract is concluded. While moral hazard, also called post-contractual opportunism, moral chance or moral risk can occur during the transaction (Akerlof, 1970). The famous example of opportunistic behavior can be found in the transaction between General Motors and Fisher Body in 1926 (Klein, 2000).

For opportunism to take place, two main factors must exist: uncertainty and information asymmetry. The introduction of the concept of uncertainty by Knight (1921) significantly changed the economic conception according to which all claims are supposed to be predictable (cited by Williamson, 2010). The absolute certainty or prediction of all events that may emerge in the future is an implausible illustration.

According to the TCT, the existence of the firm and the expansion of its size can be partly due to the perceived uncertainty outside. With regard to information asymmetry, the economic agent and, in contrast to neoclassical analysis, has limited, not perfect, rationality. This neologism was introduced by Simon (1957). According to the author, the so-called organizational man, unlike the hypothesis of substantial rationality, has partial information and is characterized by a behavior of simple satisfaction. He stops his research when he finds a satisfactory solution for the level of aspiration and not the maximum (cited by Williamson, 2002).

Contrary to the neoclassical model according to which contractors have perfect rationality in a certain environment, the homo-economicus has become a homo-contractor in the post-Coasian literature. The limited rationality of contractors in an uncertain environment creates a situation of information asymmetry, a strong possibility of opportunistic behavior and an indisputable contractual incompleteness.

The informational imbalance between homo-contractors reinforces the degree of prediction of opportunistic behavior. Opportunism is thus becoming an undeniable reality in the economic world. The instinctive nature of the individual, who is essentially selfish in his vocation to hold or even conceal the information he possesses, cannot be identified by environmental certainty, perfect rationality or contractual completeness.

\section{Internal or external growth: effect of opportunism}

In the post-Coasian analysis that has been deployed to date, making the perfect decision that better achieves established objectives while reducing costs is a major challenge in today's economy. The increasing complexity of endogenous and exogenous transactions makes any economic and managerial approach a great challenge.

Choosing to use external transactions means sharing rights and responsibilities with a legally independent actor. This balanced sharing of all kinds of ex-ante and ex-post information remains unfeasible due to the instinctive nature of the individual who often seeks to maximize his personal utility. As a result, an organizational imbalance has emerged between the two poles of the bipolar relationship. The possibility of the emergence of opportunistic behavior by a party remains a highly conceivable case, unless one of them will exercise exhaustive control and monitoring procedures to narrow such behavior. In this situation, each of the contractors will be obliged to respect, monitor and apply the contractual clauses mentioned in the contract. However, these strategies remain extremely costly for the firm that undertakes them. For its part, the TCT never encourages the use of external structures in the event of strong potential opportunism. This economic approach, which focuses on reducing a firm's total costs by reducing transaction costs, assumes that an inward orientation is the appropriate solution (Williamson, 1979).

Whatever the market structure adopted; opportunism is conceivable by the client firm. Although the classic contract that governs market relations is almost complete and opens only an arrow space for such behavior to emerge, but the probability that the producer and/or seller in the market will behave in an opportunistic manner is possible. The informational benefit is focused on this actor since the transaction in question is located in the field in which he carries out his strategic activity. Pre-contractual opportunism therefore threatens the client firm (Aubert et al, 1996).

As for the hybrid structure of economic relationships, the relatively long duration between independent parties leaves a strong possibility of the emergence of opportunism in this bipolar relationship. Admittedly, inter-firm cooperation is characterized by a high degree of internal and external uncertainty before during and after the contractual phase. Opportunism often remains the factor that prevents client firms from choosing such an 
Financial Markets, Institutions and Risks, Volume 3, Issue 4, 2019

ISSN (online) - 2521-1242 ISSN (print) - 2521-1250

organizational form. The service provider may disclose or falsify information that threatens its selectivity by the client firm. Thus, post-contractual opportunism is predictable when it seeks to tip the transaction towards its own profit (Aubert et al, 1996).

On the other hand, the hierarchical structure that designates the inside of the firm identifies or even cancels out any kind of opportunistic behavior. The employment contract between the superior and the subordinate includes meticulous and diverse contractual clauses designed to ensure longevity in the relationship between the two parties. This specific relationship is called by Williamson (1975) a voluntary subordination; because individuals accept commands and orders from the upper part by making a calculation between the contributions provided and the remuneration received. The unilateralist decision-making in the firm leaves no room for opportunistic behavior to manifest itself. The firm therefore prefers to internalize the transaction rather than confront the opportunism of external actors.

\section{The methodological approach of research}

To confirm the major role that opportunism plays in determining the firm's boundaries, a literature review was chosen. This research methodology will allow us to identify the influence that opportunism has on the firm's changing boundaries according to the scientific contributions published after the Post-Coasian analysis. In other words, we want to answer the following question:

Is there a difference between what the TCT predicts and the conclusions of the work on the role of opportunism in determining the firm's boundaries?

To answer this question, it is necessary to highlight the nature of the relationship between opportunism and the Sourcing decision, which should take the following form:

H1: The relationship is always positive between opportunism and the growth of the firm (Insourcing);

$\mathrm{H} 2$ : The relationship is always negative between opportunism and external growth (Market, or Cooperation).

\section{$\underline{1 \text { st step: Electronic exploration: }}$}

Without delimiting the publication dates of the preliminary works, our literature review was completed in June 2019, where all the scientific works published in the big journals were sent. A time interval was not created in our study to include older articles that focus on the same topic. In fact, the previous studies have given considerable enrichment to the literature regardless of the subject of analysis.

To carry out this research, the following criteria were applied in our electronic exploration:

1-Databases: we have accessed various well-known and rich databases in the field to increase our investigation framework. Google Scholar, Scopus, Sciencesdirect and JSTOR have enabled us to reach a large number of works on the same subject.

2-The concepts used: to have a maximum number of works, we used all the words that refer directly or indirectly to the organizational forms. Sourcing, Insourcing, Outsourcing, Make-Or-Buy, Market, Hierarchy, Vertical integration are the concepts used.

3-The nature of the work: we limited ourselves to synthesizing only scientific articles. According to several authors, articles published in journals remain the main reference for the researcher to expose a new scientific question (Hamilton and Ives, 1982; Donohue and Fox, 2000).

The result of the electronic investigation allowed us to obtain a total of 1371 scientific articles. In this step, the methodology recommended by Swanson and Ramiller (1993) was followed, based on a summary analysis of abstracts of the collected work.

After reading the abstracts, it appeared to us that not all of these articles are useful in our research. Many of them do not serve our primary purpose. This comes down to the following arguments:

-The multidisciplinary nature of the concept, which sometimes involves a single concept, requires careful analysis in order to remove its real meaning. The interdisciplinary between economic and managerial sciences and other research fields makes the concepts intertwined among others.

-The perception studied, because dealing with the Sourcing issue from a client firm's point of view is different from that of the service provider or the relationship with him. What interests us in this work is the perception of a firm that is facing the dichotomy: internal solutions/external solutions. 
Financial Markets, Institutions and Risks, Volume 3, Issue 4, 2019

ISSN (online) - 2521-1242 ISSN (print) - 2521-1250

-The geographical proximity between the client firm and the service provider. This criterion allows us to move away from articles devoted to studying Offshoring as a particular form of outsourcing. This type of articles focuses on the rationale for Offshoring, i. e. a comparison of Offshoring with other outsourcing strategies without having anything to say about the Sourcing decision itself.

-Ex-post analysis of organizational decision: where research that focuses on the benefits or risks of outsourcing has been eliminated. What interests us is the reason that precedes Sourcing's decision, namely: the ex-ant analysis of such a decision.

-The methodological criterion of the article with reference to Alavi and Carlson (1992) and Claver and others (2000). According to the authors, theoretical studies play only a secondary role and are intended to provide a conceptual framework for a particular phenomenon.

2nd step: Analysis of the articles:

After applying these criteria, these 1371s were filtered to obtain a final list of 93 articles intended to directly reveal the Sourcing decision. These works are classified by year as follows:

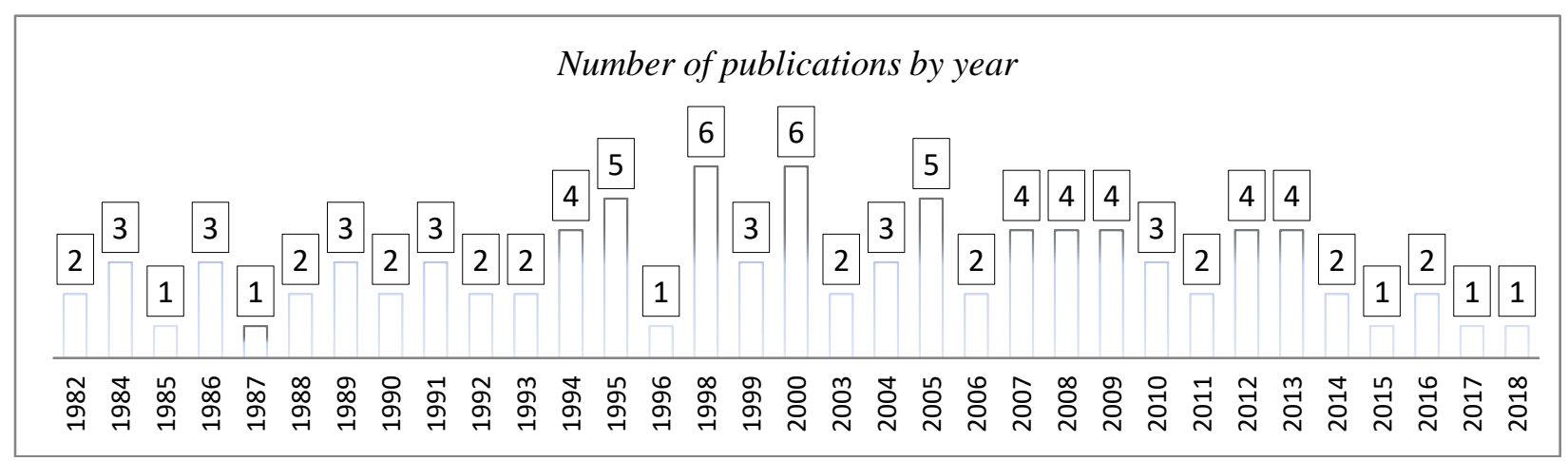

Figure 1. Number of publications by year

Source: according to the authors depending on the results of the electronic investigation.

As noted above, a time interval has not been set either upstream or downstream, as it is strong to say that the older articles have enriched the conceptual scope of the Sourcing decision by encouraging the authors to highlight other issues for further research.

The theoretical approach most commonly used by researchers over the past several decades is TCE. This theory represents a main conceptual basis to which researchers refer to justify the change in the firm's boundaries. The TCT perspective has taken on this notoriety because the assumptions of this theory have most often justified the organizational behaviors of the firms studied. In addition, the predictive models of the latter are effectively compatible with the strategies followed by the firms. Of these 93 articles dealing with the Sourcing issue, $82 \%$ are dominated by the TCT perspective. The rest is divided between $\mathrm{RBV}^{1}$, other secondary theories ${ }^{2}$ and some technical factors related to the function for which the firm is facing the Sourcing decision.

With regard to opportunism, this factor is highlighted by the authors as one of the pillars of TCE. Admittedly, the effect that both forms of opportunism have on the firm's organizational orientation is indisputable, but the concretization of this impact in the academic literature does not reflect its real importance in determining the firm's boundaries. The following table ranks the determinants of TCE according to their citation in the body of work in our analysis.

Table. 2. The TCE pillars according to their redundancy

\begin{tabular}{|l|l|}
\hline Factors & Redundancy \\
\hline TCT & 6 \\
\hline Asset specificity & 38 \\
\hline Frequency & 2 \\
\hline Uncertainty & 39 \\
\hline Opportunism & 7 \\
\hline
\end{tabular}

Source: according to the authors depending on the results of the LR.

\footnotetext{
${ }^{1}$ Resource based view

${ }^{2}$ Ex: evolutionist theory, institutional theory, agency theory.
} 
Financial Markets, Institutions and Risks, Volume 3, Issue 4, 2019

ISSN (online) - 2521-1242 ISSN (print) - 2521-1250

Among $82 \%$ of articles devoted to presenting the perspective of research to reduce transaction costs, it seems to us that the authors focus on opportunism only $8 \%$. Despite its indisputable importance in the issue of organizational choice, the authors generally neglect its decisive impact on the question of the firm's boundary dynamics. For most authors, it is the specificity of the assets that deserves to be the centre of analysis of their studies and is the main factor to be considered. Certainly, the specificity of assets has remained the main source of costs since Williamson's early analyses. Consequently, it is always seen as the primary object of study for any scientific contribution seeking to frame the Sourcing decision by the TCT predictions.

Perceived for a long time as a concept that contradicts trust, the opportunism eventually provoked by the service provider favors the internal solution. The client firm prefers to internalize a transaction rather than confront such behavior, as it will have to devote a significant portion of its costs to control and monitoring procedures to identify such behavior. Indeed, TCE implies an orientation within the firm if the degree of likelihood of opportunistic behavior is high. From this perspective, the external structure expands if the provider/seller is unable to engage in illegal behavior.

The following table summarizes the work that emphasizes opportunism as a determining factor in the firm's organizational direction.

Table 3. Works that have examined opportunism

\begin{tabular}{|l|l|l|}
\cline { 2 - 3 } \multicolumn{1}{l|}{} & Nature of the study & Sector \\
\hline Pisano (1991) & $\begin{array}{l}\text { A study of R\&D for the production and marketing function through data } \\
\text { analysis }\end{array}$ & Biotechnology \\
\hline $\begin{array}{l}\text { González-D'iaz and others } \\
(2000)\end{array}$ & A study of 278 Spanish firms between 1987 and 1992 & Different \\
\hline $\begin{array}{l}\text { Anderson and others } \\
(2000)\end{array}$ & A case study in a firm focusing on the metal casting business & Automobile \\
\hline Mayer and Salomon (2006) & A study of 405 firm contracts & Technologic \\
\hline McIvor (2008) & A case study of 7 firms & different \\
\hline McIvor (2009) & A case study of 3 firms & different \\
\hline Brewer and others (2014) & A study of 1717 firms analyzing the procurement function & Electronic \\
\hline
\end{tabular}

Source: according to the authors depending on the results of the RL.

In their studies, Pisano (1991), González-D'1az and others (2000), Mayer and Salomon (2006), and McIvor (2008) confirm the negative effect that opportunism has on Outsourcing. The authors find that the strong opportunism between the parties has pushed the client firms studied to redirect themselves within these frontiers. A positive relationship was therefore found between opportunism and internal structure. These findings clearly confirm what the TCT predicts.

On the other hand, opportunism and the strategic position of resources as a single compound factor are tested by both McIvor (2009) and Brewer and others (2014). The authors find a negative relationship between these two factors and Outsourcing. In other words, these authors confirm the negative effect that this factor has on external growth and the assumptions of TCT have been supported a second time.

However, Anderson and others (2000) find in their article that ex-post opportunism has an antagonistic effect for a firm that is facing a Sourcing decision for the first time. In another way, this study contradicts what the TCT stipulates and confirms a negative relationship between opportunism and internal growth. This observation can be justified according to our point of view by the fact of experience, because for the firm that is following a step towards changing its borders for the first time only partially takes into account all the different possible circumstances, of which opportunism is an example.

Excluding the study by Anderson and others (2000), all these studies confirmed the negative impact of opportunism on the expansion of external relations, i. e. a percentage of $86 \%$. Indeed, the TCE predictions have been almost confirmed in the work included in this literature review.

\section{Conclusion}

It must be noted that opportunism is an illegal behavior often perceived in a dual relationship between two legally independent parties. The origins of the latter are both external and internal uncertainty and information asymmetry. These two sources of opportunism are undeniable characteristics of the Post-Coasian economy. Consequently, neglecting or rejecting the effect that opportunism has on the firm's border dynamics is unworkable. 
Financial Markets, Institutions and Risks, Volume 3, Issue 4, 2019

ISSN (online) - 2521-1242 ISSN (print) - 2521-1250

The concept of trust, informational transparency or informational balance between the parties remains a dream for both theorists and practitioners. This dream is difficult if not impossible to apply as long as maximizing personal utility is the first objective of any economic actor.

According to transaction cost theory, opportunism is a crucial factor in determining transaction costs and therefore the governance structure that should be chosen. In fact, the opportunism that may have emerged from the party with more information is a major source of cost, as the party will have to devote high control procedures to identifying such behavior. The internal structure is therefore the most appropriate. This economic rule is confirmed both in the literature and in the actual practices of firms.

We have indicated in this paper the strong predictability of the TCE on the Sourcing issue. Authors have really revealed the impact that opportunism has on organizational change in the firm by positively influencing the firm's internal expansion and negatively extending the external structure.

The center of all scientific work on the same subject in the same line as Williamson's theory reinforces the TCT's predictability towards the Sourcing decision. Certainly, this work supports the confirmatory framework of this theory by focusing on the behavioral characteristic of the transaction of which opportunism is a part.

This work thus makes it possible to open up new areas of research that were previously neglected. It is therefore a question of resizing the applicability of TCT in a contemporary economy characterized by a computerization of the bipolar relationship, a flexible conceptualization of the knowledge of the actors involved in the transaction and an interdependent complementarity between different factors previously considered autonomous.

\section{References}

1. Akerlof G. A. (1970). The Market for 'Lemons': Qualitative Uncertainty and the Market Mechanism, Quarterly Journal of Economics, 84, 488-500.

2. Alavi M., Carlson P. (1992). A review of MIS research and disciplinary development, Journal of Management Information Systems, 8(4), 45-62.

3. Anderson S.W, Glenn D., Sedatole K.L. (2000). Sourcing parts of complex products: evidence on transactions costs, high-powered incentives and ex-post opportunism, Accounting, Organizations and Society, 25, 723-749.

4. Aubert, B. A., Rivard, S., Patry, M. A. (1996). Transaction cost approach to outsourcing behavior: some empirical evidence, Information and Management, 30(2), 51-64.

5. Brewer B., Wallin C., Ashenbaum A. (2014). Outsourcing the procurement function: Do actions and results align with theory? Journal of Purchasing \& Supply Management, 20, 186-194.

6. Claver E., Gonzalez R., Llopis J. (2000). An analysis of research in information systems, Information and Management, 37(4), 181-195.

7. Donohue J.M., Fox J.B. (2000). A multi-method evaluation of journals in the decision and management sciences by US academics, OMEGA, 28(1).

8. González M., Arruñada B., Fernández A., (2000). Causes of subcontracting: evidence from panel data on construction firms, Journal of Economic Behavior \& Organization, 42, 167-187.

9. Hamilton S., Ives B. (1982). Knowledge Utilization among MIS Researchers, MIS Quarterly, 20(3), 6177.

10. Imai K., Itami H. (1984). Interpenetration of Organization and Market: Japan's Firm and Market in Comparison with the US, International Journal of Industrial Organization, 6(4), 285-310.

11. Klein B. (2000). Fisher-GM and the nature of the firm, Journal of Law and Economics, 43, $105-141$.

12. Mayer K.J., Salomon R.M., (2006). Capabilities, Contractual Hazards, and Governance: Integrating Resource-Based and Transaction Cost Perspectives, The Academy of Management Journal, 49, 5, 942959.

13. McIvor R. (2008). What is the right outsourcing strategy for your process? European Management Journal, 26, 24-34.

14. McIvor R. (2009). How the transaction cost and resource-based theories of the firm inform outsourcing evaluation, Journal of Operations Management, 45-63.

15. Menard K. (2004). The Economics of Hybrid Organizations, Journal of Institutional and Theoretical Economics, 160, 345-376.

16. Pisano G. (1991). The governance of innovation: Vertical integration and collaborative arrangements in the biotechnology industry, Research Policy, 20, 237-249. 
17. Williamson O. (1971). The Vertical Integration of Production: Market Failure Considerations, American Economic Review, 61, 112-123.

18. Williamson, O. (1973). Markets and Hierarchies: Some Elementary Considerations, The American Economic Review, 63, 2, 316-325.

19. Williamson, O. (1979). Transaction Cost Economics: The Governance of Contractual Relations, 22, 233261. Journal of Law and Economics

20. Williamson, O. (1981). The Economics of Organization: The Transaction Cost Approach, American Journal of Sociology, 87, 548-577.

21. Williamson O. (1988). The Logic of Economic Organization, Journal of Law, Economics, \& Organization, $4(1), 65-93$

22. Williamson O. (1991a): Comparative Economic Organization: The Analysis of Discrete Structural Alternatives, Administrative Science Quarterly, 36, 269-296.

23. Williamson O. (1992b): Markets, hierarchies, and the Modern Corporation, An unfolding perspective, Journal of Economic Behavior and Organization, 17, 335-352.

24. Williamson O. (1993a): Transaction Cost Economics and Organization Theory, Industrial and Corporate Change, 2(2), 107-156.

25. Williamson, O. E., (2000). The new institutional economics: taking stock, looking ahead, Journal of Economic Literature, 38, 595-613.

26. Williamson O. (2002). The Theory of the Firm as Governance Structure: From Choice to Contract, Journal of Economic Perspectives, 16(3), 171-195.

27. Williamson O. (2010). Transaction Cost Economics: The Natural Progression, American Economic Review, 100, 673-690. 